CAKRAWALA - Repositori IMWI | Volume 4, Nomor 2, Oktober 2021

p-ISSN: 2620-8490; e-ISSN: 2620-8814

\title{
PENGARUH DISPLAY PRODUCT DAN PRICE DISCOUNT DI MASA PANDEMIC COVID-19 TERHADAP IMPULSE BUYING PRODUK FOOD SUPERMARKET (STUDI PADA KONSUMEN TOSERBA YOGYA CIRANJANG)
}

\author{
Intan Rike Febriyanti \\ Institut Manajemen Wiyata Indonesia \\ Email: rikeintan@gmail.com \\ Galih Raspati \\ Institut Manajemen Wiyata Indonesia \\ Email: galih_raspati@yahoo.com \\ Umban Adi Jaya \\ Institut Manajemen Wiyata Indonesia \\ Email: Umbanadijaya01@gmail.com \\ Andika Aryadinata \\ Institut Manajemen Wiyata Indonesia \\ Email: Andikaaryadinata98@gmail.com
}

\begin{abstract}
Abstrak
Tujuan dari penelitian ini adalah guna mengetahui dampak pembelian impulsif makanan di supermarket terhadap display produk dan penurunan harga. Metode yang digunakan adalah metode kuantitatif asosiatif, penyebaran kuesioner menggunakan sampel sebanyak 100 orang atas teknik intent sampling atas kriteria konsumen Ciranjang Department Store Yogyakarta. Penelitian ini menggunakan uji instrumental dalam uji validitas dan reliabilitas, analisis deskriptif adalah teknik analisis data yang digunakan, uji normalitas, uji multikolinearitas dan uji heteroskedastisitas serta uji linieritas multivariat yang terdiri dari uji hipotesis (test to test) analisis regresi. Uji F) dan dianalisis koefisien determinasi (R2) menggunakan uji hipotesis klasik. Hasil penelitian ini menunjukkan bahwa: (1) Display produk berdampak positif terhadap pembelian impulsif food di supermarket, atas nilai t-hitung sebesar 2,129 dan koefisien regresi positif sebesar 0,149; (2) Penurunan harga berdampak positif terhadap pembelian impulsif makanan di supermarket, t hitung sebesar 4,471, dan koefisien regresi positif sebesar 0,315; (3) Eksposur produk dan penurunan harga berdampak positif terhadap pembelian impulsif bahan makanan di supermarket, hasil perhitungan sebesar 27425, dan signifikansinya adalah 0,000. (4) Besarnya dampak display produk dan penurunan harga terhadap pembelian impulsif makanan supermarket ditonjolkan oleh nilai adjusted R-squared sebesar 0,348 yang menunjukkan bahwa variabel independen memiliki kemampuan $2 \%$ guna menjelaskan perubahan dependen variabel, dijelaskan oleh variabel di luar model dalam penelitian ini.
\end{abstract}

Kata Kunci: tampilan produk, potongan harga, pembelian impulsif 


\begin{abstract}
The purpose of this study was to determine the impact of impulse buying of food in supermarkets on product displays and price reductions. The method used is associative quantitative method, distributing questionnaires using a sample of 100 people based on the intent sampling technique on the criteria of consumers of Ciranjang Department Store Yogyakarta. This study uses an instrumental test in the validity and reliability test, descriptive analysis is the data analysis technique used, normality test, multicollinearity test and heteroscedasticity test and multivariate linearity test consisting of hypothesis testing (test to test) regression analysis. $F$ test) and analyzed the coefficient of determination (R2) using the classical hypothesis test. The results of this study indicate that: (1) Product display has a positive impact on impulse buying of food in supermarkets, with a t-count value of 2.129 and a positive regression coefficient of 0.149 ; (2) The decrease in price has a positive impact on impulse buying of food in supermarkets, $t$ count is 4.471, and the positive regression coefficient is 0.315; (3) Product exposure and price declines have a positive impact on impulse buying of groceries in supermarkets, the calculation result is 27425 , and the significance is 0.000. (4) The magnitude of the impact of product displays and price reductions on impulse purchases of supermarket food is highlighted by the adjusted $R$ squared value of 0.348 which indicates that the independent variable has the ability of $2 \%$ to explain changes in the dependent variable, explained by variables outside the model in this study.
\end{abstract}

Keywords: product display, discount, impulse buying 


\section{Pendahuluan}

Salah satu dampak dari COVID-19 adalah penurunan ekonomi yang tajam dan perubahan perilaku konsumen terhadap barang konsumsi dan produk sampingan. Menurut (Sheth, 2020), perubahan perilaku konsumen yang dipengaruhi oleh regulasi dan tata cara jual beli produk merupakan salah satu dampak dari kehadiran Covid-19. Atas cara ini, industri ritel akan berdampak. Sekretaris Jenderal Asosiasi Pengusaha Ritel Indonesia (APRINDO) mengatakan, semua industri ritel modern mengalami penurunan pendapatan.akibat kondisi pandemic yang tengah terjadi akibat pembatasan jam operasional toko. Yang akan mempengaruhi keputusan pembelian konsumen. Membuat retail department store mengalami penurunan omzet.

Tabel 1.

Perbandingan Sales (Qty) Reguler dan Floor Display

\begin{tabular}{|c|c|c|c|c|c|}
\hline \multirow{2}{*}{ Node } & \multirow{2}{*}{ Description } & \multicolumn{4}{|c|}{ Sales(Qty) NORMAL Sales(Qty) PANDEMIC } \\
\hline & & Regular & Floor Display & Regular f & Floor Display \\
\hline 17 & NOODLES AND PASTA & $2.946,00$ & $3.980,00$ & $2.455,00$ & $3.689,00$ \\
\hline $\mathrm{J3}$ & SEASONING & 971,93 & $1.346,89$ & 956 & $1.439,25$ \\
\hline JC & SNACKS & 931 & $1.313,00$ & 874,71 & $1.319,00$ \\
\hline JE & BEVERAGES & 920 & $1.140,00$ & 808 & $1.205,00$ \\
\hline J4 & UQUID MILK & 765 & $1.065,00$ & 715 & $1.082,00$ \\
\hline JF & MILK PRODUCT & 764 & 997 & 690 & $1.080,00$ \\
\hline JB & BISCUTS & 667 & 869 & 642 & $1.050,00$ \\
\hline JD & BREAKFAST & 556 & 867 & 558 & 802 \\
\hline 16 & COOKING OIL & 406 & 726 & 366 & 683 \\
\hline$J A$ & CONFECTIONERY & 390,99 & 454 & 352 & 596 \\
\hline J1 & LOCAL BASIC & 338 & 401,27 & 295,09 & 408,17 \\
\hline 18 & BAKING AND COOKING NEEDS & 134 & 152 & 198 & 208 \\
\hline JK & \begin{tabular}{|l|l|l} 
SYRUP & \\
\end{tabular} & 132 & 147 & 66 & 103 \\
\hline JG & BAKERY & 130 & 140 & 62 & 95 \\
\hline 15 & CANNED AND PACKED FOOD & 71 & 103 & 55 & 92 \\
\hline 9 & CIGARETTE & 61 & 87 & 39 & 71 \\
\hline$J$ & IMPORT PRODUCT & 61 & 61 & 37 & 58 \\
\hline $\mathrm{J2}$ & DRIED GOODS & 22 & 29 & 36 & 35 \\
\hline & Total (Qty) & $10.266,92$ & $13.878,16$ & $9.204,80$ & $14.015,42$ \\
\hline
\end{tabular}

Sumber : internal Toserba Yogya ciranjang

Dari Tabel 1 yaitu Tabel perbandingan sales(Qty) reguler dan floor Display di masa normal dan pandemic covid-19, dari beberapa kategori Food Supermarket terlihat bahwa sales(qty) floor Display mengalami peningkatan di masa pandemic. Dibandingkan atas sales(qty) floor Display sebelum pandemic. Menurut Intan megasari (Chief Operation Toserba yogya Ciranjang) mengatakan bahwa Display Product yang diberikan Toserba yogya ciranjang mempengaruhi terhadap pembelian konsumen di masa pandemic.

(Amiri et al., 2012) menjelaskan bahwa masyarakat dalam dunia bisnis khususnya yang berada di industri ritel harus merespon kebutuhan konsumen yang semakin beragam dan penting. Karena daya beli masyarakat sudah berubah. Guna meningkatkan pendapatan penjualan tahunan melalui belanja konsumen, pengecer harus mempertimbangkan peluang ini. Meningkatkan daya beli konsumen

adalah cara yang dapat digunakan pengecer guna bersaing di industri ritel. Belanja impulsif mengacu pada pengaturan atau penyajian produk yang sedang dijual guna membangkitkan minat dan keinginan guna berbelanja. Belanja impulsif terjadi ketika konsumen tidak terbiasa atas tampilan toko di bawah tekanan waktu, atau ketika seseorang diingatkan bahwa mereka perlu membeli sesuatu sambil melihat rak atau stan. Penempatan produk merupakan alat pemasaran yang perlu dipertimbangkan karena merupakan bagian dari insentif pembelian yang mendorong konsumen guna melakukan pembelian impulsif.

Menurut (Rahmadana, 2016) upaya menata produk agar pembeli tertarik guna melihat dan membelinya. Menurut penelitian yang dilakukan oleh (Wisesa et al., 2019), produk display berdampak positif dan signifikan terhadap pembelian impulsif konsumen di Indomaret Denpasar. Selain 
itu, penelitian (Mutiah et al., 2018) menunjukkan bahwa variabel produk yang ditampilkan berdampak signifikan terhadap variabel perilaku pembelian impulsif.

Menurut (Mulianingrum, 2010), konsumen seringkali membeli produk tanpa perencanaan sebelumnya. Saat berada di toko, sering kali ada keinginan guna membeli. Banyak faktor yang menyebabkan hal ini. Diskon yang signifikan akan menarik perhatian konsumen (Jaya et al., 2020). Konsumen akan merasa perlu membeli produk tersebut (Mutiah et al., 2018).

Kegiatan diskon dapat memicu konsumen guna melakukan pembelian impulsif. Diskon merupakan salah satu strategi promosi atas menawarkan produk atas harga yang lebih murah dari yang seharusnya (Wisesa et al., 2019). Diskon yang termasuk dalam bagian ini adalah strategi yang digunakan perusahaan guna meningkatkan keterlibatan pelanggan.

Menurut survei yang dilakukan oleh (Wisesa et al., 2019), diskon harga berdampak positif signifikan terhadap pembelian impulsif. Menurut hasil survei yang dilakukan oleh (Putri, 2020), potongan harga tidak berdampak signifikan terhadap pembelian impulsif.

Tentu saja, penelitian tentang produk yang disajikan dan penurunan harga dalam hal pengaruhnya terhadap perilaku pembelian impulsif konsumen bukanlah hal baru. Oleh karena itu, peneliti ingin mengetahui lebih jauh mengenai fenomena impulse buying yang terjadi selama masa pandemi covid-19. Department store Yogya Ciranjang, pameran merchandise dan diskon mempengaruhi dorongan guna membeli makanan di supermarket. Ini akan memberi gambaran tentang latar belakang masalah penelitian.

\section{Metode Penelitian}

Jenis penelitian yang digunakan dalam penelitian ini adalah deskriptif, yang dilengkapi atas metode yang digunakan dalam penelitian ini adalah penelitian kuantitatif atas metode Survey (Putri, 2020).

\section{Populasi dan Sampel}

Populasi adalah objek penelitian. (Sugiyono, 2017) menyatakan bahwa populasi adalah domain umum yang terdiri dari subjek atau hal-hal atas kualitas dan kepribadian tertentu yang peneliti identifikasi guna dipelajari dan kemudian dipetakan. Dalam penelitian ini, populasi yang digunakan dalam penelitian ini diwakili oleh konsumen toko Yogya Ciranjang yang melakukan transaksi belanja. Menurut (Sugiyono, 2017), sampel adalah bagian dari ukuran dan karakteristik populasi. Karena masyarakat dalam penelitian ini tidak diketahui dan dirahasiakan oleh subjek penelitian. Sampel kemudian diperoleh atas menggunakan rumus Lemeshow sebagai berikut:

$$
\mathrm{n}=\frac{\mathrm{Z}^{2} \cdot \mathrm{P}(1-\mathrm{P})}{\mathrm{d}^{2}}
$$

Keterangan :

$\mathrm{n}=$ Jumlah sampel

$\mathrm{Z}=$ Tingkat kepercayaan $=1.96$

$\mathrm{P}=$ Prevalensi outcome, maksimal estimasi $50 \%=0,5$

$\mathrm{d}=$ Tingkat ketelitian atau sampling error $10 \%=0,1$

Berdasarkan rumus maka,

$$
\mathrm{n}=\frac{1.96^{2} \cdot 0,5(1-0,5)}{0,1^{2}}=96,04
$$

Seperti yang terlihat dari perhitungan di atas, besar sampel yang akan diambil guna 
penelitian ini adalah 96 responden, namun guna mendapatkan hasil yang lebih akurat, peneliti akan membulatkannya menjadi 100 responden. Teknik pengambilan sampel yang digunakan adalah teknik purposive sampling. Teknik purposive sampling digunakan guna individu atas karakteristik tertentu. Persyaratan sampel dalam penelitian ini adalah konsumen yang melakukan transaksi belanja di department store Ciranjang Yogyakarta.

\section{Operasionalisasi Variabel}

$\mathrm{X} 1$ adalah produk showcase yang terdiri dari 4 metrik, visibilitas situs, penempatan produk, aksesibilitas, dan sentimen positif.

$\mathrm{X} 2$ adalah penurunan harga yang terdiri dari 6 metrik yang memotivasi konsumen guna membeli dalam jumlah besar, memprediksi promosi pesaing, mendukung penawaran massal, penghematan, jumlah diskon, frekuensi diskon.

$\mathrm{Y}$ adalah akuisisi impulsif dan terdiri dari 4 indikator yaitu spontanitas, kurangnya pertimbangan konsekuensi, keinginan membeli yang tiba-tiba diikuti oleh emosi, dan ketidakmampuan guna menekan keinginan batin.

\section{Pengumpulan Data}

Penelitian ini menggunakan dua teknik pengumpulan data, yaitu:

\section{Wawancara}

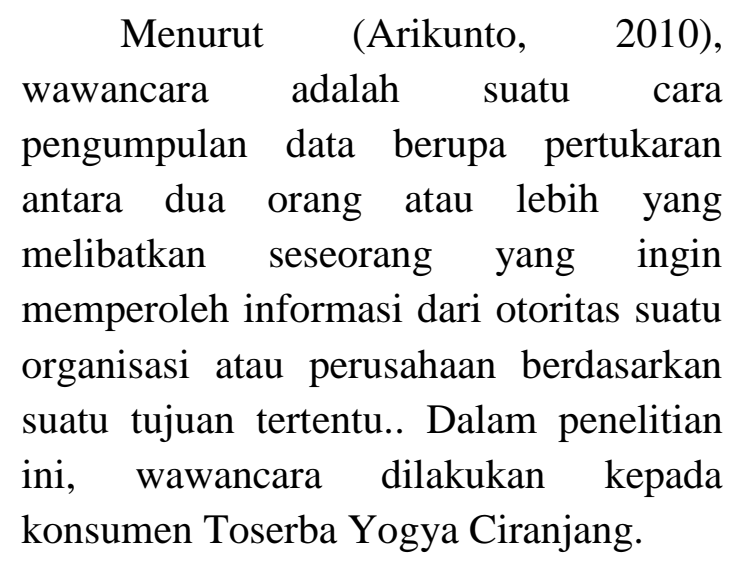

\section{Kuesioner}

Menurut (Arikunto, 2010), kuesioner adalah teknik pengumpulan data atas menyebarkan kuesioner yang memberikan serangkaian pertanyaan tertulis yang sebelumnya diajukan kepada responden. Dalam penelitian ini, kuesioner disebarkan secara online melalui tautan Google from.

\section{Pengujian Validitas}

Menurut (Arikunto, 2010), validitas adalah ketepatan suatu instrumen dalam mengukur apa yang hendak diukur. Validitas adalah alat ukur yang menunjukkan tingkat keabsahan atau keakuratan suatu alat dalam mengukur apa yang hendak diukur.

Dalam SPSS, teknik pengujian yang biasa digunakan guna menguji validitas menggunakan korelasi bivariat Pearson (Pearson product moment) dan korelasi total yang disesuaikan. Pengujian ini menggunakan uji dua sisi atas tingkat signifikansi 0,05. Ciri-ciri tes ini adalah sebagai berikut:

1. Jika $\mathrm{r}$ menghitung tabel $\mathrm{r}$, maka alat atau item tersebut memiliki hubungan yang signifikan (valid) terhadap skor total.

2. Jika jumlah $\mathrm{r}<\mathrm{r}$ dalam tabel, berarti alat atau elemen pertanyaan tidak berhubungan erat atas skor total (tidak valid).

\section{Pengujian Reliabilitas}

Menurut (Arikunto, 2010), hal itu menunjukkan bahwa reliabilitas merupakan alat yang cukup baik dan cukup andal guna pengumpulan data. Koefisien reliabilitas diketahui dari besarnya koefisien alpha $(\alpha)$. 
Suatu variabel dikatakan reliabel jika memberikan nilai cronbach's alpha $>0,6$.

\section{Uji Asumsi Klasik}

Pengujian hipotesis klasik merupakan syarat statistik yang harus dipenuhi dalam analisis regresi linier berganda berbasis kuadrat terkecil biasa (OLS). Lakukan pengujian ini guna mendapatkan hasil regresi yang terukur dan mendapatkan hasil yang spesifik. Uji hipotesis klasik yang umum digunakan adalah uji normalitas, uji linieritas berganda, uji heterogenitas dan uji autokorelasi.

\section{Hasil Penelitian dan Pembahasan}

Uji validitas digunakan dalam penelitian guna mengukur validitas kuesioner penelitian. Suatu kuesioner dikatakan valid jika pertanyaan/pernyataan dalam kuesioner tersebut memberikan indikasi yang baik tentang apa yang hendak diukur oleh kuesioner penelitian. Hasil yang dihasilkan kemudian dibandingkan atas nilai pada $r$ tabel pada taraf signifikansi 0,05. Jika nilai pada tabel aritmatika $r$ adalah positif maka dapat dinyatakan valid, jika tabel aritmatika $r$ elemen tersebut dinyatakan tidak valid. Hasil penelitian menunjukkan bahwa semua indikator valid guna semua elemen pernyataan yang ada sebagai indikator. Kesimpulan ini diambil dari perbandingan angka $r$ setiap artikel atas tabel $r$ yang memiliki nilai lebih besar dari hasil perhitungan guna semua artikel, menunjukkan bahwa tidak ada angka $r$ yang lebih kecil dari nilainya. $r$ tabel adalah 0,195 yang berarti $r$ hitung $r$ tabel, sehingga semua elemen dapat dianggap valid.

\section{A. Uji Reliabilitas}

Uji reliabilitas adalah pengujian yang diperoleh atas menghitung koefisien alpha atas menggunakan metode cronbach's alpha guna mengetahui konsistensi jawaban responden dari waktu ke waktu. Jika hasilnya > 0,06 maka alat tersebut memiliki nilai reliabilitas yang tinggi. Suatu variabel dikatakan reliabel jika nilai Cronbach Alpha $>$ 0,60. Pada hasil penelitian ini, varian Cronbach Alpha Display Product (X1) memiliki nilai 0,769 sehingga mewakili reliabilitas. Variabel tingkat diskonto (X2) sebesar 0,838 yang dinyatakan reliabel, dan variabel impulse buying (Y) sebesar 0,701, juga dinyatakan reliabel. Dapat disimpulkan bahwa ketiga variabel tersebut reliabel.

\section{B. Uji Asumsi Klasik}

Hasil uji hipotesis klasik berupa uji normalitas, uji linieritas berganda dan uji heterogenitas.

\section{Tes postur normal}

Hasil data menunjukkan bahwa nilai signifikansi (Asyump.sig 2 tailed) dapat ditentukan pada kolom KolmogorovSmirnov, yaitu 0,154 . Nilai signifikansi lebih besar dari 0,05 $(0,154>0,05)$, nilai residualnya normal. Dari sini dapat disimpulkan bahwa model regresi dampak gabungan dua variabel bebas $\mathrm{X} 1$ dan $\mathrm{X} 2$ terhadap variabel terikat $\mathrm{Y}$ memenuhi syarat normalitas data.

\section{Uji Multikolinieritas}

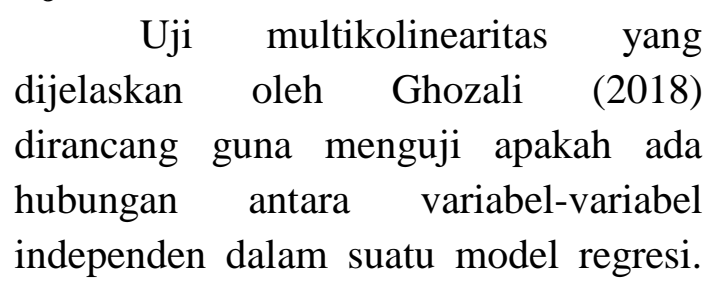
Batas umum guna menampilkan beberapa hubungan linier adalah nilai toleransi 0,10 atau sama atas nilai VIF 10.

Hasil pengujian menunjukkan bahwa nilai korelasi antar variabel bebas 
yaitu variabel penawaran produk (X1) dan variabel diskon harga (X2) memiliki nilai VIF keluaran yang sama yaitu $1,534<10$, dan nilai toleransi keluaran masing-masing variabel juga sama. identik. identik. Angka yang sama muncul $0,652>0,1$, sehingga dapat disimpulkan bahwa tidak ada hubungan multilinier antara variabel bebas yang diteliti.

\section{Uji heteroskedastisitas}

Pengujian heterogenitas menurut Imam Al-Ghazali (2018) bertujuan guna mengetahui apakah pengamatan yang tersisa berbeda atas pengamatan lainnya dalam model regresi.

Scatter plot dalam pengolahan data SPSS menunjukkan bahwa komponen scatter plot tidak membentuk pola, titiktitik tersebar secara acak, dan terdistribusi di atas dan di bawah angka 0 pada sumbu $\mathrm{Y}$, dan tidak terdapat heterogenitas pada variabel X2 dan Y.

\section{Uji Hipotesis}

Pengujian hipotesis menggunakan analisis regresi linier berganda guna memprediksi signifikansi hubungan antara variabel bebas dan variabel terikat. Selain itu, penelitian ini menggunakan software SPSS guna uji $\mathrm{T}$ dan $\mathrm{F}$ serta perhitungan statistik, dan hasil analisis regresi linier berganda dari penelitian ini.

\section{Uji Regresi Linear Berganda}

Hasil analisis di atas atas menggunakan SPSS 25 for Windows, hasil persamaan regresi berganda adalah sebagai berikut: $\mathrm{Y}=$ $1,548+0,149 \mathrm{X} 1+0,315 \mathrm{X} 2+\mathrm{e}$ Arti persamaan regresinya adalah sebagai berikut:
1. Nilai konstanta $=1,548$, menunjukkan dampak positif terhadap variabel tampilan produk dan penurunan harga.

2. Variabel produk yang ditampilkan $(\mathrm{X} 1)=$ 0,149 artinya jika produk yang ditampilkan (X1) bertambah 1 (satu) maka tingkat pembelian impulsif konsumen Yogya Ciranjang akan meningkat sebesar 0,149.

\section{E. Uji $\mathbf{t}$}

Hasil SPSS menunjukkan bahwa tingkat signifikansi uji-t variabel Tampilan Produk adalah 0,036 yang lebih kecil dari 0,05 , dan nilai thitung yang dihasilkan adalah 2,129 yang lebih tinggi dari nilai ttabel $(\mathrm{Dk}=\mathrm{n}-\mathrm{k}-1)=1,98$, maka Ho ditolak dan Ha diterima. Jadi hipotesis yang diajukan adalah "produk yang ditampilkan berdampak positif dan signifikan terhadap pembelian impulsif". diterima. Tingkat signifikansi variabel Harga Diskon adalah 0,000 yang lebih kecil dari 0,05 , sedangkan nilai thitung yang diperoleh sebesar 4,471, lebih besar dari nilai $\mathrm{t}$-Tabel $(\mathrm{Dk}=\mathrm{n}-\mathrm{k}-1)=1,98$; jadi Ho ditolak dan $\mathrm{Ha}$ diterima. Oleh karena itu hipotesis yang diajukan adalah bahwa "penurunan harga berdampak positif dan signifikan terhadap pembelian impulsif". diterima. Cara pengambilan keputusan pengujian parsial dalam analisis regresi dapat diringkas sebagai berikut:

A. Produk yang ditampilkan (X1) berdampak signifikan secara parsial terhadap variabel Y (impulse buying).

b.Variabel penurunan harga (X2) berdampak signifikan secara parsial terhadap variabel Y (impulse buying).

\section{F. Uji F}

Output SPSS pada tabel Anova di atas menunjukkan bahwa variabel Product 
Display dan Markdown memiliki nilai $\mathrm{F}$ hitung sebesar 27.425 dan nilai signifikansi sebesar 0,000. Nilai F hitung lebih besar dari F tabel 27,425 > 3,09 (DK = n-3-1 = 3,09) dan nilai signifikansi guna variabel display produk dan markdown lebih kecil dari nilai $0,000<0,05$. Oleh karena itu, dapat disimpulkan bahwa baik produk yang ditampilkan maupun penurunan harga mempengaruhi pembelian impulsif.

\section{G. Pembahasan Penelitian}

\section{Mendemonstrasikan dampak produk terhadap pembelian impulsif makanan supermarket.}

Berdasarkan hasil survey konsumen department store Yogya Ciranjang, hasil analisis deskriptif konsumen department store Yogya Ciranjang pada variabel display produk relatif tinggi, dan Yogya Ciranjang Universal memiliki nilai rata-rata variabel display produk tertinggi. Simpan laporan produk atas mengelompokkan item berdasarkan tujuan. Dan skor minimal dalam pernyataan pembelian pemilihan supermarket berdasarkan produk yang dipajang adalah unik dan menarik. Artinya, responden percaya bahwa barangbarang Yogya Ciranjang Toserba dikelompokkan berdasarkan kegunaannya, dan mereka enggan guna memilih tempat membeli berdasarkan tampilan produknya yang unik dan menarik. Penelitian ini juga menunjukkan bahwa displaying product berdampak positif dan signifikan terhadap impulse buying makanan yang diperoleh dari hasil uji regresi statistik atas nilai t-hitung sebesar 2,129 dan nilai signifikansi yang lebih rendah sebesar 0,036. koefisien regresi positif sebesar 0,05 dan 0,149, maka hipotesis H1 dalam penelitian ini terbukti, bahwa "produk yang dipajang berdampak positif dan signifikan terhadap pembelian impulsif". Hasil uji-t menunjukkan hasil yang signifikan, yaitu $0,037<0,05$. Oleh karena itu dapat disimpulkan bahwa variabel produk yang ditampilkan berdampak positif dan signifikan terhadap akuisisi impulsif.

2. Dampak penurunan harga terhadap pembelian impulsif makanan supermarket.

Berdasarkan hasil Survei Konsumen Yogya Ciranjang diketahui bahwa hasil analisis deskriptif variabel diskon harga konsumen Yogya Ciranjang tergolong tinggi, dan nilai rata-rata tertinggi dari variabel harga diskon adalah pernyataan kesenangan membeli. didiskon karena menghemat lebih banyak biaya, dan nilai minimum ada dalam pernyataan preferensi. Beli produk atas diskon ganda, bahkan jika Anda tidak menyukainya. Artinya responden senang membeli barang diskon karena lebih hemat dan enggan membeli barang diskon ganda dan tidak menyukainya. Penelitian ini juga menunjukkan bahwa potongan harga berdampak positif dan signifikan terhadap pembelian impulsif makanan supermarket, yang diperoleh dari hasil uji regresi statistik atas nilai 4,471, nilai signifikansi 0,000 lebih kecil dari 0,05 , dan regresi . Nilai koefisien yang positif adalah 0,315 , maka 
hipotesis H1 dalam penelitian ini menunjukkan bahwa "penurunan harga berdampak positif dan signifikan terhadap pembelian impulsif", dan hasil uji t menunjukkan hasil yang signifikan, yaitu $0,000<0,05$. Oleh karena itu dapat disimpulkan bahwa variabel harga atas diskon berdampak positif dan signifikan terhadap pembelian impulsif.

\section{KESIMPULAN DAN SARAN \\ Simpulan}

Hasil analisis yang dilakukan peneliti dirancang guna menjawab pertanyaanpertanyaan yang telah dikemukakan sebelumnya dalam rumusan pertanyaan. Dari penelitian dan pembahasan di atas, dapat disimpulkan bahwa display dan price reduction berdampak signifikan terhadap motivasi beli konsumen di department store Yogya Ciranjang.

\section{Saran}

Penelitian yang dilakukan oleh peneliti menunjukkan hasil bahwa variabel Display Product berdampak terhadap impulse buying. Dan berdasarkan hasil penelitian variabel Display Product masuk ke dalam kategori tinggi. Saran yang bisa diberikan kepada manajemen Toserba Yogya Ciranjang guna meningkatkan Impulse Buying. Saran-saran tersebut antara lain:

1. Apabila Toserba Yogya Ciranjang ingin lebih meningkatkan Impulse Buying nya, maka sebaiknya manajemen Toserba Yogya Ciranjang lebih berfokus kepada ketersediaan barang dan pengelompokan barang di area display sesuai atas kegunaannya. Sehingga Impulse Buying konsumen akan tetap stabil atau bahkan meningkat.
2. Hasil penelitian variabel Price Discount menunjukkan hasil bahwa variabel Price Discount berdampak terhadap Impulse Buying. Maka dari itu diharapkan bisa memanfaatkan secara maksimal tingkat Price Discount yang dimiliki agar Impulse Buying semakin meningkat. Salah satunya atas memperhatikan waktu pemberian diskon mengingat lokasi toserba yogya ciranjang berdekatan atas pabrik-pabrik industri yang mayoritas konsumen toserba yogya ciranjang adalah perempuan yang bekerja sebagai pegawai swasta. Pemberian diskon yang tepat akan membuat impulse buying semakin tinggi.

3. Bagi peneliti yang akan melakukan penelitian di masa yang akan datang sebaiknya memperluas variabel dan pengukuran variabel penelitian sehingga dapat lebih meningkatkan Impulse Buying konsumen Toserba Yogya Ciranjang. Selain itu, diharapkan penelitian selanjutnya dapat mengkaji lebih dalam tentang Display Product yang pada penelitian ini berdampak terhadap Impulse Buying konsumen Toserba Yogya Ciranjang agar diperoleh gambaran yang lebih lengkap lagi sehingga diharapkan hasil penelitian yang akan datang lebih sempurna dari penelitian ini.

\section{Daftar Pustaka}

Amiri, F., Jasour, J., Shirpour, M., \& Alizadeh, T. (2012). Evaluation of effective fashionism involvement factors effects on impulse buying of customers and condition of interrelation between these factors. Journal of Basic and Applied Scientific Research, 2(9), 9413-9419. 
Arikunto, S. (2010). Metode peneltian. Jakarta: Rineka Cipta.

Jaya, U. A., Bagja, S. I., \& Somantri, B. (2020). Pengaruh Price dan Product Quality Terhadap Costumer Loyalty Internet Indosat Ooredo di Sukabumi. Cakrawala Repositori IMWI, 3(1), 3342.

Mulianingrum, W. (2010). Analisis FaktorFaktor yang Mempengaruhi Impulse Buying Pada Merek Super T-Shirt (Studi pada Pengunjung Matahari Department Store Singosaren).

Mulyati, S., \& Jaya, U. A. (2020). Pengaruh Kualitas Produk dan Harga Terhadap Keputusan Pembelian HP iPhone. Winter Journal: Imwi Student Research Journal, 1(1), 22-30.

Mutiah, I., Parawansa, D., \& Munir, A. R. (2018). The effect of visual merchandising, product display dan store atmosphere on impulse buying behavior (Case study on Matahari department store in Makassar city). Hasanuddin Journal of Applied Business and Entrepreneurship, 1(2), 88-103.

Putri, N. A. (2020). Pengaruh Brand Knowledge Dan Hedonic Shopping Value Terhadap Impulse Buying Dengan Positive Emotion Sebagai Moderasi. SIMBA: Seminar Inovasi Manajemen, Bisnis, Dan Akuntansi, 2.

Rahmadana, N. M. S. (2016). Pengaruh display produk dan suasana toko terhadap pembelian impulsif di minimarket eramart cabang lembuswana samarinda. EJournal Ilmu Administrasi Bisnis FISIP Unmul, 4(3), 687.

Sheth, J. (2020). Impact of Covid-19 on consumer behavior: Will the old habits return or die? Journal of Business Research, 117, 280-283.

Sugiyono, F. X. (2017). Neraca pembayaran: Konsep, Metodologi dan penerapan (Vol. 4). Pusat Pendidikan Dan Studi Kebanksentralan (PPSK) Bank Indonesia.

Wisesa, I. G. B. S., Setiawan, I. K., Utami, N. L. P. M. P., Yasa, N. N. K., \& Jatra, M. (2019). Pengaruh Store Atmosphere, Display Product, Dan Price Discount Terhadap Impulse Buying (Studi kasus pada Indomaret di kota Denpasar) I Putu Widya Artana. E-Jurnal Ekonomi Dan Bisnis Universitas Udayana, 8, 369-394. 